\title{
Molecular typing and virulence markers of Yersinia enterocolitica strains from human, animal and food origins isolated between 1968 and 2000 in Brazil
}

Correspondence

Juliana P. Falcão

jufalcao@fcfrp.usp.br
Received 22 May 2006 Accepted 21 July 2006

\author{
Juliana P. Falcão, ${ }^{1,2}$ Deise P. Falcão, ${ }^{3}$ André Pitondo-Silva, ${ }^{2}$ \\ Ana Carolina Malaspina ${ }^{3}$ and Marcelo Brocchi ${ }^{2,4}$
}

\author{
${ }^{1}$ Departamento de Análises Clínicas, Toxicológicas e Bromatológicas, Faculdade de Ciências \\ Farmacêuticas de Ribeirão Preto-USP, Av. do Café, s/no- Campus Universitário USP, \\ Ribeirão Preto, SP, 14040-903, Brazil \\ ${ }^{2}$ Departamento de Biologia Celular, Molecular e Bioagentes Patogênicos, Faculdade de \\ Medicina de Ribeirão Preto-USP, Av. Bandeirantes 3900, Ribeirão Preto, SP, 14049-900, \\ Brazil \\ ${ }^{3}$ Departamento de Ciências Biológicas, Faculdade de Ciências Farmacêuticas-UNESP, Rodovia \\ Araraquara-Jaú Km1, Araraquara, SP, 14801-902, Brazil \\ ${ }^{4}$ Departamento de Microbiologia e Imunologia, Instituto de Biologia-UNICAMP, Caixa Postal: \\ 6109, Campinas, SP, 13083-862, Brazil
}

\begin{abstract}
Molecular typing and virulence markers were used to evaluate the genetic profiles and virulence potential of 106 Yersinia enterocolitica strains. Of these strains, 71 were bio-serotype 4/O :3, isolated from human and animal clinical material, and 35 were of biotype $1 \mathrm{~A}$ or 2 and of diverse serotypes, isolated from food in Brazil between 1968 and 2000. Drug resistance was also investigated. All the strains were resistant to three or more drugs. The isolates showed a virulence-related phenotype in the aesculin, pyrazinamidase and salicin tests, except for the food isolates, only two of which were positive for these tests. For the other phenotypic virulence determinants (autoagglutination, $\mathrm{Ca}^{++}$dependence and Congo red absorption), the strains showed a diverse behaviour. The inv, ail and $y s t \mathrm{~A}$ genes were detected in all human and animal strains, while all the food isolates were positive for inv, and $3 \%$ of them positive for ail and $y$ stA. The presence of virF was variable in the three groups of strains. The strains were better discriminated by PFGE than by enterobacterial repetitive intergenic consensus PCR (ERIC-PCR). A higher genomic similarity was observed among the $4 / O: 3$ strains, isolated from human and animal isolates, than among the food strains, with the exception of two food strains possessing the virulence genes and grouped close to the $4 / O: 3$ strains by ERIC-PCR. Unusually, the results revealed the virulence potential of a bio-serotype $1 \mathrm{~A} / \mathrm{O}: 10$ strain, suggesting that food contaminated with $Y$. enterocolitica biotype $1 \mathrm{~A}$ may cause infection. This also suggests that ERIC-PCR may be used as a tool to reveal clues about the virulence potential of $Y$. enterocolitica strains. Furthermore, the results also support the hypothesis that animals may act as reservoirs of $Y$. enterocolitica for human infections in Brazil, an epidemiological aspect that has not been investigated in this country, confirming data from other parts of the world.
\end{abstract}

\section{INTRODUCTION}

Yersinia enterocolitica is the most prevalent Yersinia species connected to disease in humans (Bottone, 1999; RobinsBrowne, 2001). It has also frequently been isolated from

Abbreviations: AMK, amikacin; AMP, ampicillin; CEF, cephalothin; CFZ cephazolin; EGT, ERIC genomic type; ERIC-PCR, enterobacterial repetitive intergenic consensus PCR; FOX, cefoxitin; PGT, pulsedfield genomic type. animals, food and the environment (Fredriksson-Ahomaa et al., 1999; Thoerner et al., 2003; Falcão et al., 2004).

$Y$. enterocolitica is responsible for gastroenteritis and other syndromes in humans and animals (Bottone, 1999). Human clinical infections with $Y$. enterocolitica most frequently occur after ingestion of food and/or contaminated water (Robins-Browne, 2001; Salyers \& Whitt, 2002).

Y. enterocolitica strains have traditionally been classified by a well-established typing system, based on a combination of 
biochemical and serological tests that enable the differentiation of the strains into diverse bio-serotypes (Aleksic \& Bockemühl, 1999). Also, pathogenic strains are related to some phenotypic characteristics, such as pyrazinamidase production, aesculin hydrolysis, salicin fermentation, calcium dependence, autoagglutination and Congo red absorption (Bottone, 1999). Molecular genetic studies have emphasized the importance of a virulence plasmid (pYV) that encodes various virulence genes, among them $\operatorname{vir} \mathrm{F}$, which is an important transcriptional regulator of other plasmid genes, as well as the role of chromosomal virulence genes that mediate cell invasion (inv and ail) and produce a thermostable enterotoxin $(y s t \mathrm{~A})$, among others (Carniel, 1995; Cornelis et al., 1998).

Molecular methods have also been used for typing and in epidemiological studies of $Y$. enterocolitica. The molecular methods most frequently used include restriction analysis of both plasmids (Nesbakken et al., 1987; Kapperund et al., 1990) and chromosomes (Blumberg et al., 1991), randomly amplified polymorphic DNA analysis (Rasmussen et al., 1994), ribotyping (Andersen \& Saunders, 1990; Lobato et al., 1998) and PFGE (Najdenski et al., 1994; Saken et al., 1994; Iteman et al., 1996; Fredriksson-Ahomaa et al., 2004). The enterobacterial repetitive intergenic consensus-PCR (ERICPCR) technique has not been used extensively, and its real potential as a tool for typing and in epidemiological studies of $Y$. enterocolitica has yet to be recognized (Sachdeva \& Virdi, 2004; Wojciech et al., 2004).

Y. enterocolitica is not often isolated and studied in Brazil, making it difficult to establish the involvement of this bacterium as a causative agent of human and animal diseases in this country, or to estimate the impact of its presence in food. In particular, to our knowledge, there are no data about the virulence potential of biotype 1A strains isolated from food in Brazil, except for two studies that investigated the production of the heat-stable enterotoxin (ST) by Yersinia strains isolated from samples of meat and milk (Tibana et al., 1987; Warnken et al., 1987). Only environmental strains of this biotype have been analysed for the presence of virulence markers (Falcão et al., 2004). In order to answer some of the questions, the aim of the present study was to characterize some phenotypic and genotypic virulence markers of $Y$. enterocolitica, isolated from human patients, animals and foodstuffs in Brazil, and to assess the level of genomic similarity and possible relatedness among these strains by PFGE and ERIC-PCR. All of these data have been brought together to elucidate more thoroughly the epidemiology of Y. enterocolitica in Brazil, where its importance as an enteropathogen has been neglected.

\section{METHODS}

Bacterial strains. A total of 106 strains of $Y$. enterocolitica, isolated between 1968 and 2000 from human patients (37 strains), animals (34 strains) and food (35 strains), from different regions, states and cities of Brazil, were analysed in this study. They were selected from the collection of the Yersinia Reference Laboratory in Brazil (School of Pharmaceutical Sciences, UNESP, Araraquara, São Paulo State). It is important to point out that these strains had already been isolated when received at the Reference Laboratory for further confirmation and typing.

The strains were systematically chosen to represent the range of types of the collection. This was done by selecting the most prevalent bioserotypes from each of the sources studied, and ensuring that all strains chosen had been isolated from different sources.

The 37 human strains, obtained from different patients, were all isolated from diarrhoeic faeces, the 34 animal strains (from different animals) from pig faeces (24 strains), dog faeces (three strains), rat faeces (one strain), bull faeces (one strain) and marmoset hepatic abscess (five strains). The remaining 35 strains were isolated from various types of food, such as raw and pasteurized milk, pork sausage, pork meat, chicken, bull's liver, ice, beef and lettuce. These 106 strains were isolated by investigators of various institutions located in different cities, states and regions of Brazil: 76 strains from the Southeast Region, comprising São Paulo State (28 strains from the capital, São Paulo, three from Botucatu, four from Campinas, 14 from Araraquara, seven from Ribeirão Preto and one strain from São José do Rio Preto) and Rio de Janeiro State (19 strains from the capital, Rio de Janeiro); 25 strains from the South Region, from Rio Grande do Sul State (21 strains from Porto Alegre) and Paraná State (two strains from Curitiba and two from Londrina); and five strains from the Northeast Region, from Pernambuco State (from the capital, Recife).

Bio-sero-phagetype classification. The isolates were all assigned to biotypes as recommended in Aleksic \& Bockemühl (1999). They were serotyped according to Wauters et al. (1991) and phage typed according to Nicolle et al. (1976).

Drug resistance. All the isolates were tested for drug resistance by disc diffusion, following the National Commitee for Clinical Laboratory Standards (2001) guidelines. The following antimicrobial drugs and quantities were used: ampicillin (AMP),10 $\mu \mathrm{g}$; cephalothin (CEF), $30 \mu \mathrm{g}$; cefotaxime (CTX), $30 \mu \mathrm{g}$; cefoxitin (FOX), $30 \mu \mathrm{g}$; cephazolin (CFZ), $30 \mu \mathrm{g}$; amikacin (AMK), $30 \mu \mathrm{g}$; gentamicin (GEN), $10 \mu \mathrm{g}$; kanamycin (KAN), $30 \mu \mathrm{g}$; streptomycin (STR), $10 \mu \mathrm{g}$; tobramycin (TOB), $10 \mu \mathrm{g}$; nalidixic acid (NAL), $30 \mu \mathrm{g}$; norfloxacin (NOR), $10 \mu \mathrm{g}$; ofloxacin (OFX), $5 \mu \mathrm{g}$; tetracycline (TET), $30 \mu \mathrm{g}$; chloramphenicol (CHL), $30 \mu \mathrm{g}$; imipenem (IPM), $10 \mu \mathrm{g}$; and sulfamethoxazole-trimethoprim (SXT), $25 \mu \mathrm{g}$. All the drugs were bought from the CECON Laboratory (Ribeirão Preto, São Paulo, Brazil).

Phenotypic virulence characteristics. The following tests were performed as described in the cited texts: temperature-dependent autoagglutination, salicin fermentation and aesculin hydrolysis (Farmer et al., 1992), calcium-dependent growth and Congo red absorption (Riley \& Toma, 1989), and pyrazinamidase production (Kandolo \& Wauters, 1985).

Detection of the genes inv, ail, ystA and virF by PCR. Genomic DNA was extracted as described by Covone et al. (1998) and its concentration determined as in Sambrook \& Russell (2001). The general PCR procedure was performed by the method given in Saiki et al. (1988), using 2.0 U Taq DNA polymerase. The primers used and the number of base pairs of the respective products are displayed in Table 1. The PCR reaction conditions used for detection of the various genes were as described in the following: for inv, Rasmussen et al. (1994); for ail, Nakajima et al. (1992); for ystA, Ibrahim et al. (1997); and for virF, Wren \& Tabaqchali (1990). The Y. enterocolitica strains Ye7660 and Ye197, isolated from diarrhoeic faeces of human origin and food respectively, contain all the tested 
Table 1. Primers used to detect the inv, ail, ystA and virF genes in $Y$. enterocolitica

\begin{tabular}{|c|c|c|c|}
\hline Gene & Primer name & Sequence $\left(5^{\prime} \rightarrow 3^{\prime}\right)$ & Amplicon size (bp) \\
\hline$i n v$ & YC2 & GAA CTG CTT GAA TCC CTG AAA ACC G & \\
\hline ail & Ail2 & CCC CCA GTA ATC CAT AAA GG & \\
\hline$y s t \mathrm{~A}$ & $\operatorname{Pr} 2 \mathrm{a}$ & A ATG CTG TCT TCA TTT GGA GCA & 145 \\
\hline$v i r \mathrm{~F}$ & VirF2 & ACT CAT CTT ACC ATT AAG AAG & \\
\hline
\end{tabular}

genes and were used as positive controls. Reactions without DNA as a template or with genomic DNA of Escherichia coli DH5- $\alpha$ strain (New England Biolabs) were used as negative controls.

In order to check the reproducibility of the experiments, the PCR reactions were repeated two or three times for some strains.

The PCR products were analysed by agarose gel electrophoresis and visualized by UV light after staining of the gel with ethidium bromide $\left(0 \cdot 5 \mu \mathrm{g} \mathrm{ml}^{-1}\right)$.

ERIC-PCR. Genomic DNA was extracted as described as above. One hundred nanograms DNA template was used in each PCR reaction. The PCR reaction mixture also contained $1.25 \mathrm{mM}$ of each deoxyribonucleotide, $5 \mathrm{mM} \mathrm{MgCl} 2,1 \cdot 0 \mathrm{U}$ Klentaq1 DNA polymerase (Ab Peptides) and $50 \mathrm{pmol}$ each primer. The primers used were ERIC1R ( $5^{\prime}$-ATGTAAGCTCCTGGGGATTCAC- $\left.3^{\prime}\right)$ and ERIC2 (5'AAGTAAGTGACTGGGGTGAGCG-3'), as described by Versalovic et al. (1991). The cycles used in the PCR were: initial cycle of $7 \mathrm{~min}$ at $94{ }^{\circ} \mathrm{C}, 30$ cycles of $30 \mathrm{~s}$ at $94^{\circ} \mathrm{C}, 1 \mathrm{~min}$ at $52^{\circ} \mathrm{C}$ and $8 \mathrm{~min}$ at $65^{\circ} \mathrm{C}$, and final cycle of $10 \mathrm{~min}$ at $65^{\circ} \mathrm{C}$.

The ERIC-PCR reaction was repeated at least twice for each strain to verify the reproducibility of the experiment. Reactions without the DNA template were used as negative controls.

The ERIC-PCR products were analysed by agarose gel electrophoresis, the gel being stained with ethidium bromide $\left(0.5 \mu \mathrm{g} \mathrm{ml}^{-1}\right)$ and visualized by UV light.

Data analysis was performed with GelCompar II 2.0 for Windows (Applied Maths). Only the bands between 300 and $5000 \mathrm{bp}$ in size were included in the analysis. The similarity dendrogram was constructed by the unweighted pair group method with arithmetic averages (UPGMA), using the Dice similarity index. A standard molecular weight ladder was included twice on each gel, to allow normalization of images for valid comparisons of fingerprints on different gels. The standard used was the $1 \mathrm{~kb}$ Plus DNA Ladder (Invitrogen-Life Technologies).

The ERIC genomic types (EGTs) were considered to be different if any band difference was found in their fragments.

PFGE. The genomic DNAs were prepared in agarose plugs, using a protocol described by Liu et al. (1993), with a few modifications. Bacteria were grown overnight in brain heart infusion (BHI) broth (Oxoid) at $28^{\circ} \mathrm{C}$. Each culture was diluted 1:50 in $10 \mathrm{ml} \mathrm{BHI}$ and reincubated at $28{ }^{\circ} \mathrm{C}$, until reaching $\mathrm{OD}_{600} 0 \cdot 6-0 \cdot 9$. The cultures were centrifuged at $2300 \mathrm{~g}$ for $3 \mathrm{~min}$ at $4{ }^{\circ} \mathrm{C}$, and the sediment was resuspended in $500 \mu \mathrm{l}$ cell-suspension buffer $(100 \mathrm{mM}$ Tris, $\mathrm{pH} 7 \cdot 2$, $20 \mathrm{mM} \mathrm{NaCl}, 100 \mathrm{mM}$ EDTA). The cell suspension was mixed with an equal volume of $2 \%$ low-melting-point agarose (Bio-Rad Laboratories) and cast in DNA-plug moulds. The agarose plugs were treated for $2 \mathrm{~h}$ in a lysis solution $(100 \mathrm{mM}$ Tris, $\mathrm{pH} 7 \cdot 2,20 \mathrm{mM}$ $\mathrm{NaCl}, 100 \mathrm{mM}$ EDTA, $1 \mathrm{mg}$ lysozyme $\left.\mathrm{ml}^{-1}, \mathrm{pH} 7 \cdot 6\right)$ at $37^{\circ} \mathrm{C}$ and transferred to $5 \mathrm{ml}$ deproteination solution $(0 \cdot 25 \mathrm{M}$ EDTA, $\mathrm{pH} 9 \cdot 0$, $0.5 \%$ sarcosyl, $5 \mathrm{mg}$ proteinase $\mathrm{K} \mathrm{ml}^{-1}$ ) for $12-16 \mathrm{~h}$ at $50{ }^{\circ} \mathrm{C}$. The plugs were washed four times with TE buffer $(100 \mathrm{mM}$ Tris, $1 \mathrm{mM}$ EDTA), with $1 \mathrm{mM}$ PMSF added to the second wash. The plugs were stored in $0.5 \mathrm{M}$ EDTA at $4{ }^{\circ} \mathrm{C}$ until use.

Before digestion, plugs were washed in TE buffer (100 mM Tris, $1 \mathrm{mM}$ EDTA) for $1 \mathrm{~h}$. They were digested with $40 \mathrm{U}$ XbaI (New England Biolabs) overnight. Macrorestriction fragments were resolved by counter-clamped homogeneous electric field electrophoresis in a CHEF-DRIII apparatus (Bio-Rad Laboratories), using an electric field of $6 \mathrm{~V} \mathrm{~cm}^{-1}$ and angle of $120^{\circ} \mathrm{C}$ (Guiyoule et al., 1997). Migration of the DNA fragments was achieved in $0.5 \times$ Tris/borate/EDTA buffer and $1.0 \%$ agarose maintained at $14{ }^{\circ} \mathrm{C}$. Pulse times were ramped from 1 to $10 \mathrm{~s}$ over $29 \mathrm{~h}$.

Restriction fragments were visualized under UV light after the gel was stained with ethidium bromide $\left(0 \cdot 5 \mu \mathrm{g} \mathrm{ml}^{-1}\right)$

The genomic profile obtained was analysed as described above for ERIC-PCR. A standard molecular weight ladder was included three times on each gel to allow comparisons of fingerprints on different gels. The molecular weight standard used was Lambda Ladder PFG Marker (New England Biolabs).

The pulsed-field genomic types (PGTs) were assessed as described above for the ERIC-PCR technique.

Discrimination index (DI). The discriminatory power of PFGE and ERIC-PCR was compared by Simpson's diversity index, as presented by Hunter \& Gaston (1998).

\section{RESULTS AND DISCUSSION}

\section{Bio-sero-phagetyping}

The bio-sero-phagetypes and source of origin of the $106 \mathrm{Y}$. enterocolitica strains used in this study are presented in Table 2. All 37 strains isolated from human diarrhoeic faeces were bio-sero-phagetyped as 4/O:3/VIII and were isolated between 1979 and 2000 in various regions of Brazil, mostly from the Southeast region (31 strains). A similar result was observed for the animal isolates ( 34 strains), 33 being biosero-phagetyped as 4/O:3/VIII and just one as IXa. These animal strains were isolated from various types of animal clinical material, between 1968 and 1985, all coming from the Southeast (10 strains) and South (24 strains) regions. The 35 strains isolated from diverse types of food were of 
Table 2. Bio-sero-phagetypes and source of $106 \mathrm{Y}$. enterocolitica strains isolated from human diarrhoeic faeces (37), animal clinical material (34) and food (35)

\begin{tabular}{|c|c|c|c|c|}
\hline No. of strains & Bio-sero-phagetype & \multicolumn{3}{|c|}{ (No. of strains) source of isolate } \\
\hline 33 & 4/O :3/VIII & & $\begin{array}{l}\text { (5) Marmoset hepatic abscess, } \\
\text { (3) dog faeces, (24) pig faeces, } \\
\text { (1) rat faeces }\end{array}$ & \\
\hline \multirow[t]{3}{*}{7} & $1 \mathrm{~A} / \mathrm{O}: 5 / \mathrm{Xz}$ & & & (1) Raw milk \\
\hline & & & & (5) Pasteurized milk \\
\hline & & & & (1) Pork sausage \\
\hline 1 & $1 \mathrm{~A} / \mathrm{O}: 5 / \mathrm{Xo}$ & & & (1) Chicken \\
\hline 5 & $1 \mathrm{~A} / \mathrm{O}: 5,27 / \mathrm{Xz}$ & & & $\begin{array}{l}\text { (1) Pasteurized milk, (1) bull's liver, } \\
\text { (1) pork sausage, (2) raw milk }\end{array}$ \\
\hline 3 & $1 \mathrm{~A} / \mathrm{O}: 13,7 / \mathrm{Xz}$ & & & (2) Meat, (1) lettuce \\
\hline 1 & $1 \mathrm{~A} / \mathrm{O}: 7,8 / \mathrm{Xo}$ & & & (1) Pasteurized milk \\
\hline 1 & $2 / \mathrm{O}: 14 / \mathrm{Xz}$ & & & (1) Raw milk \\
\hline 2 & $1 \mathrm{~A} / \mathrm{O}: 6,31 / \mathrm{Xz}$ & & & (1) Pasteurized milk, (1) pork meat \\
\hline 1 & $2 / \mathrm{O}: 7,8 / \mathrm{Xz}$ & & & (1) Pasteurized milk \\
\hline 1 & $1 \mathrm{~A} / \mathrm{O}: 10 / \mathrm{Xo}$ & & & (1) Milk \\
\hline 1 & $1 \mathrm{~A} / \mathrm{O}: 10 / \mathrm{Xz}$ & & & (1) Raw milk \\
\hline 1 & $1 \mathrm{~A} / \mathrm{O}: 10,34 / \mathrm{Xo}$ & & & (1) Raw milk \\
\hline 1 & $1 \mathrm{~A} / \mathrm{O}: 4,33 / \mathrm{Xz}$ & & & (1) Chicken \\
\hline 3 & $1 \mathrm{~A} / \mathrm{O}: 14 / \mathrm{Xo}$ & & & (1) Beef, (2) pork sausage \\
\hline 2 & $1 \mathrm{~A} / \mathrm{O}: 8,19 / \mathrm{Xz}$ & & & (2) Raw milk \\
\hline
\end{tabular}

bio-sero-phagetypes other than $4 / \mathrm{O}: 3 / \mathrm{VIII}$ or IXa, with a prevalence of biotype $1 \mathrm{~A}$ and serogroups $\mathrm{O}: 5$ and $\mathrm{O}: 5,27$. These food strains were all isolated from the Southeast region between 1980 and 1995. The predominance of strains isolated in the Southeast and South regions of Brazil is probably the result of more efficient medical and laboratory practices than those of other regions of Brazil.

It is interesting to mention that until now the Yersinia Reference Laboratory has never received any Y. enterocolitica of bio-serotype 4/O:3 isolated from food. Only strains biotyped as 1A or 2 (of diverse serotypes) have been isolated from foodstuffs in Brazil and received by the Reference Laboratory (Falcão, 1987, 1991; D. P. Falcão and others, unpublished results). However, this does not mean that food cannot function as a vehicle for human infection with $Y$. enterocolitica 4/O:3 in Brazil. Data from other studies have indicated that the conventional culture methods generally used to detect and isolate pathogenic Y. enterocolitica from food are not efficient (Nesbakken et al., 1991; FredrikssonAhomaa \& Korkeala, 2003; Fredriksson-Ahomaa et al., 2006). Future studies using molecular detection methods, such as DNA hybridization and PCR, in association with conventional methods will be needed to better evaluate this phenomenon in Brazil. In the specific case of the food strains studied here, it is not possible to discuss the procedures used to isolate these strains, as they were isolated by different investigators and sent to the Yersinia Reference Laboratory for confirmation and typing only.

Additionally, none of the strains evaluated here can be related to a disease outbreak, as all were isolated from sporadic cases. To our knowledge, no outbreak related to $Y$. enterocolitica has been reported so far in Brazil (Falcão, 1987, 1991; D. P. Falcão and others, unpublished results).

\section{Drug-resistance profile}

The tests of drug resistance showed that all the $Y$. enterocolitica strains were resistant to at least AMP, CEF and CFZ. Of the 37 Y. enterocolitica strains isolated from humans, only two were resistant to further drugs. Similar results were observed for the $34 \mathrm{Y}$. enterocolitica strains obtained from various animal clinical isolates. Three of these animal strains, besides AMP, CEF and CFZ, were also resistant to AMK. The majority of the 35 strains isolated from food $(74 \cdot 3 \%)$ were resistant to FOX, as well as AMP, CEF and CFZ. 
The resistance profile obtained is in agreement with previous studies, in which resistance to AMP and many cephalosporins is frequently observed (Stock \& Wiedemann, 1999; Tzelepi et al., 1999; White et al., 2002; Stock \& Wiedemann, 2003). In fact, the expression of $\beta$-lactamase enzymes $\mathrm{A}$ and $\mathrm{B}$ has already been associated with $Y$. enterocolitica, Yersinia intermedia and Yersinia frederiksenii (Stock et al., 1999, 2000; Stock \& Wiedemann, 1999, 2003; Tzelepi et al., 1999).

\section{Phenotypic tests related to virulence}

The results of the phenotypic tests related to virulence are presented in Table 3 . All 37 isolates from humans and 34 isolates from animals showed virulence-related phenotypes with respect to aesculin hydrolysis, salicin fermentation and pyrazinamidase production, with the exception of one human strain (Ye33) that hydrolysed aesculin. In complete contrast, only one food-related strain (Ye197) of bio-serophagetype $2 / \mathrm{O}: 7,8 / \mathrm{Xz}$, isolated from pasteurized milk, gave similar results.

The phenotypic tests related to the expression of plasmid genes had variable results. A total of $73.0 \%$ (27) of human strains and $41 \cdot 2 \%$ (14) of animal strains were positive for the tests of autoagglutination at $37^{\circ} \mathrm{C}$, calcium dependence at $37^{\circ} \mathrm{C}$ and Congo red absorption. Otherwise, only strain Ye197, among those isolated from food, was positive for these tests.

These results confirm published data, which show a wellestablished correlation between pathogenic biotype and virulence behaviour in these phenotypic tests (Farmer et al., 1992; Bauab et al., 1995).
We can also conclude that although the plasmid was present in the majority of the strains of human and animal origin, as revealed by the detection of the virF gene (Table 3), in some of these strains, the plasmid genes relating to the expression of autoagglutination, calcium dependence and Congo red absorption were not expressed. Analysing these results, we could speculate that these genes were silenced by a mutation or that the conditions used in the phenotypic assays were not appropriate to induce their expression in some of the strains.

\section{Detection of virulence genes}

The incidence of virulence genes detected in the various bioserotypes is presented in Table 3. The inv gene was detected in all the strains studied. The ail and $y s t \mathrm{~A}$ genes were detected in all the strains isolated from humans and animals, but only in two strains isolated from food. Despite the presence of virulence genes, these two food strains were not implicated as a direct cause of foodborne disease. The vir $\mathrm{F}$ gene showed a variable incidence, being detected in $94.6 \%$ (35 strains), $61 \cdot 8 \%$ (21 strains) and $2 \cdot 9 \%$ (1 strain) of isolates from humans, animals and food, respectively.

These results indicate the virulence potential of the strains isolated from human patients and animals, and reinforce their association with the diseases in the humans and animals from which they were isolated. This was expected, since the bio-serotype $4 / 0: 3$ is the one most frequently isolated from infections caused by $Y$. enterocolitica in Brazil and Europe (Falcão, 1987; Carniel, 2001; Robins-Browne, 2001).

Regarding the food strains, while the inv gene was detected in all of them, as expected, since this gene is common to pathogenic and non-pathogenic strains, the ail and $y$ st A

Table 3. Phenotypic virulence characteristics and PCR detection of virulence genes in $106 \mathrm{Y}$. enterocolitica strains isolated from human diarrhoeic faeces (37), animals (34) and foodstuffs (35)

\begin{tabular}{|c|c|c|c|}
\hline \multirow[t]{2}{*}{ Phenotypic tests/virulence genes } & \multicolumn{3}{|c|}{ Number of positive strains (\%), bio-serotypes } \\
\hline & Human origin & Animal origin & Food origin \\
\hline \multicolumn{4}{|l|}{ Expression of plasmid genes } \\
\hline Autoagglutination at $37^{\circ} \mathrm{C}$ & $27(73 \cdot 0 \%), 4 / O: 3$ & $14(41 \cdot 2 \%), 4 / \mathrm{O}: 3$ & $1(2 \cdot 9 \%), 2 / \mathrm{O}: 7,8$ \\
\hline $\mathrm{Ca}^{++}$dependence at $37^{\circ} \mathrm{C}$ & $27(73 \cdot 0 \%), 4 / O: 3$ & $14(41 \cdot 2 \%), 4 / \mathrm{O}: 3$ & $1(2 \cdot 9 \%), 2 / O: 7,8$ \\
\hline Congo red absorption & $27(73 \cdot 0 \%), 4 / O: 3$ & $14(41 \cdot 2 \%), 4 / \mathrm{O}: 3$ & $1(2 \cdot 9 \%), 2 / O: 7,8$ \\
\hline \multicolumn{4}{|l|}{ Other phenotypic tests } \\
\hline Aesculin hydrolysis & $36(97 \cdot 3 \%), 4 / O: 3$ & $34(100 \%), 4 / O: 3$ & $1(2 \cdot 9 \%), 2 / O: 7,8$ \\
\hline Salicin fermentation & $37(100 \%), 4 / O: 3$ & $34(100 \%), 4 / O: 3$ & $1(2 \cdot 9 \%), 2 / O: 7,8$ \\
\hline Pyrazinamidase production & $37(100 \%), 4 / O: 3$ & $34(100 \%), 4 / O: 3$ & $1(2 \cdot 9 \%), 2 / \mathrm{O}: 7,8$ \\
\hline \multicolumn{4}{|l|}{ Presence of virulence genes } \\
\hline$i n v$ & $37(100 \%), 4 / O: 3$ & $34(100 \%), 4 / O: 3$ & $35(100 \%)^{*}$ \\
\hline ail & $37(100 \%), 4 / O: 3$ & $34(100 \%), 4 / O: 3$ & $2(5 \cdot 7 \%), 1 \mathrm{~A} / \mathrm{O}: 10,2 / \mathrm{O}: 7,8$ \\
\hline$y s t \mathrm{~A}$ & $37(100 \%), 4 / O: 3$ & $34(100 \%), 4 / O: 3$ & $2(5 \cdot 7 \%), 1 \mathrm{~A} / \mathrm{O}: 10,2 / \mathrm{O}: 7,8$ \\
\hline$v i r \mathrm{~F}$ & $35(94 \cdot 6 \%), 4 / O: 3$ & $21(61 \cdot 8 \%), 4 / O: 3$ & $1(2 \cdot 9 \%), 2 / O: 7,8$ \\
\hline
\end{tabular}

${ }^{\star}$ The bio-serotypes of the food strains studied were: $2 / \mathrm{O}: 10 ; 1 \mathrm{~A} / \mathrm{O}: 5 ; 1 \mathrm{~A} / \mathrm{O}: 5,27 ; 1 \mathrm{~A} / \mathrm{O}: 13 ; 1 \mathrm{~A} / \mathrm{O}: 13,7 ; 1 \mathrm{~A} / \mathrm{O}: 7,8 ; 2 / \mathrm{O}: 14 ; 1 \mathrm{~A} / \mathrm{O}: 6,31$; $2 / \mathrm{O}: 7,8 ; 1 \mathrm{~A} / \mathrm{O}: 10 ; 1 \mathrm{~A} / \mathrm{O}: 10,34 ; 1 \mathrm{~A} / \mathrm{O}: 4,33 ; 1 \mathrm{~A} / \mathrm{O}: 14 ; 1 \mathrm{~A} / \mathrm{O}: 8,19 ; 1 \mathrm{AO}: 41,42 ; 1 \mathrm{~A} / \mathrm{O}: 12,25$. 
genes were detected in just two strains $(5 \cdot 7 \%)$. One of these two strains, Ye251, was biotyped as 1A, which has been treated as a non-pathogenic biotype. However, the presence of some virulence genes in a strain of this biotype confirms several reports that biotype $1 \mathrm{~A}$ is not as harmless as was once believed (Grant et al., 1998; Sulakvelidze, 2000; Tennant et al., 2003). In an outbreak of gastroenteritis in Canada described by Ratnam et al., (1982), involving nine hospital patients from the same nursery, the agent was $Y$. enterocolitica biotype 1A, serogroup O:5. In another outbreak in the UK, described by McIntyre \& Nnochiri (1986), the Y. enterocolitica strain involved was biotype 1A and serogroup $O: 6,30$. Tennant et al. (2003) have suggested that there are two subgroups of biotype $1 \mathrm{~A}$ of $Y$. enterocolitica: a group comprising pathogenic strains of clinical origin and another group comprising non-pathogenic strains of environmental origin. Thus, the isolation of Y. enterocolitica 1A/O : 10 (Ye251) from food, carrying such important virulence genes as ail and $y s t \mathrm{~A}$, is very rare (Grant et al., 1998; Singh \& Virdi, 2004), and highly undesirable, as it may represent a hazard to consumers of food contaminated by these bacteria. Although few, there are some published data showing the involvement of $Y$. enterocolitica 1A/O : 10 in human infection (Greenwood \& Hooper, 1990; Morris et al., 1991). The other food strain found to carry virulence genes in this study, Ye197, harboured all four genes (inv, ail, ystA and $v i r \mathrm{~F}$ ). This strain, isolated from pasteurized milk, was bio-sero-phagetyped as $2 / \mathrm{O}: 7,8 / \mathrm{Xz}$, and showed a virulent profile in all the phenotypic tests used, as mentioned above. According to the literature, biotype 2, associated with serogroups $\mathrm{O}: 5,27, \mathrm{O}: 9$ and $\mathrm{O}: 27$, has frequently been related to disease (RobinsBrowne, 2001). These results lead us to conclude that this strain, isolated from pasteurized milk, biotyped as 2, showing a virulence phenotype and harbouring some important virulence genes, is a strain with a potential to cause disease. Thus, rigorous control of the time and temperature of pasteurization is necessary to eliminate these micro-organisms. Additionally, our data suggest that serogroup $\mathrm{O}: 7,8$ could be added to the serogroups of $Y$. enterocolitica biotype 2 with potential to cause disease. Despite these observations, these two food strains harbouring virulence genes have not been directly implicated as the cause of any foodborne illness.

\section{ERIC-PCR and PFGE}

To examine the genomic similarity among the strains, ERIC-PCR and PFGE were employed.

All 106 Y. enterocolitica strains were analysed by the ERICPCR technique. Fig. 1(a) shows a representative set of the amplification profiles generated by ERIC-PCR with some of the studied Y. enterocolitica strains from all three sources of origin. ERIC-PCR was repeated at least twice for each strain in order to check the reproducibility of the experiments. In all cases, the same pattern of bands was found for each replicate.
ERIC-PCR grouped 84 of the strains $(79 \cdot 2 \%)$ into 10 genomic types (EGT1-EGT10), and 22 strains $(20 \cdot 8 \%)$ showed unique fingerprint profiles (EGT11-EGT32), generating a discriminatory index of $0 \cdot 908$. The $4 / \mathrm{O}: 3$ strains of human and animal origin showed high genomic similarity. These strains were discriminated into seven EGTs, forming two main groups with about $78.0 \%$ similarity. Both groups included isolates of human and animal origin only. The strains isolated from food samples and belonging to biotypes $1 \mathrm{~A}$ or 2 of various serotypes were more diverse in their fingerprints. It is important to point out that strains Ye197 (2/O: 7,8) and Ye251 (1A/O : 10), the only strains with virulence genes isolated from foods, were grouped closer (almost $70 \%$ similarity) to the strains isolated from human and animal clinical material than to the other food strains (similarity lower than $50 \%$ ).

The PFGE technique was performed on 103 Y. enterocolitica strains. Three strains isolated from food were omitted from this analysis, as they suffered DNA degradation after repeated pulsed-field runs.

Fig. 1(b) shows representative macrorestriction fragment profiles generated by some of the strains isolated from human patients. By this technique, $53.4 \%$ (55 of the analysed strains) were grouped into 15 PFGE genomic types (PGT1-PGT15), and $46 \cdot 6 \%$ (48 strains) showed unique fingerprint profiles (PGT16-PGT63), generating a discrimination index of 0.969 . Overall, 32 PGTs of $Y$. enterocolitica $4 / \mathrm{O}: 3$ were found, and again, the animal and human isolates proved to be highly similar in their fingerprint profiles, with $84.0 \%$ or more similarity for the majority of the strains (99.0 \% of the strains). Some strains isolated from human diarrhoeic faeces were grouped in the same genomic type as strains isolated from animal clinical material, and vice versa.

It may be concluded that PFGE was able to discriminate the strains better than ERIC-PCR. On the other hand, ERICPCR grouped the two food strains (Ye197 and Ye251) that carried virulence genes closer to the strains isolated from human patients and animals than to the other food strains. These results suggest that the presence or absence of particular virulence genes affects the band pattern generated by ERIC-PCR. The BLAST search for ERIC sequences on the genome of $Y$. enterocolitica strain $8081(1 \mathrm{~B} / \mathrm{O}: 8)$ did not reveal any ERIC or homologue sequences flanking virulence genes. Thus, the insertion of virulence genes such as ail and ystA between ERIC sequences probably cannot explain the differences or similarities in the band patterns of the strains generated by ERIC-PCR. In future experiments, it will be of interest to compare the degree of virulence of the two food strains that carried the virulence genes (Ye197 and Ye251) with that of strains already established as virulent, by using the in vivo mouse infection model.

Both ERIC-PCR and PFGE results suggest that animals function as $Y$. enterocolitica reservoirs for human infection, corroborating previous observations from other countries 
(a)

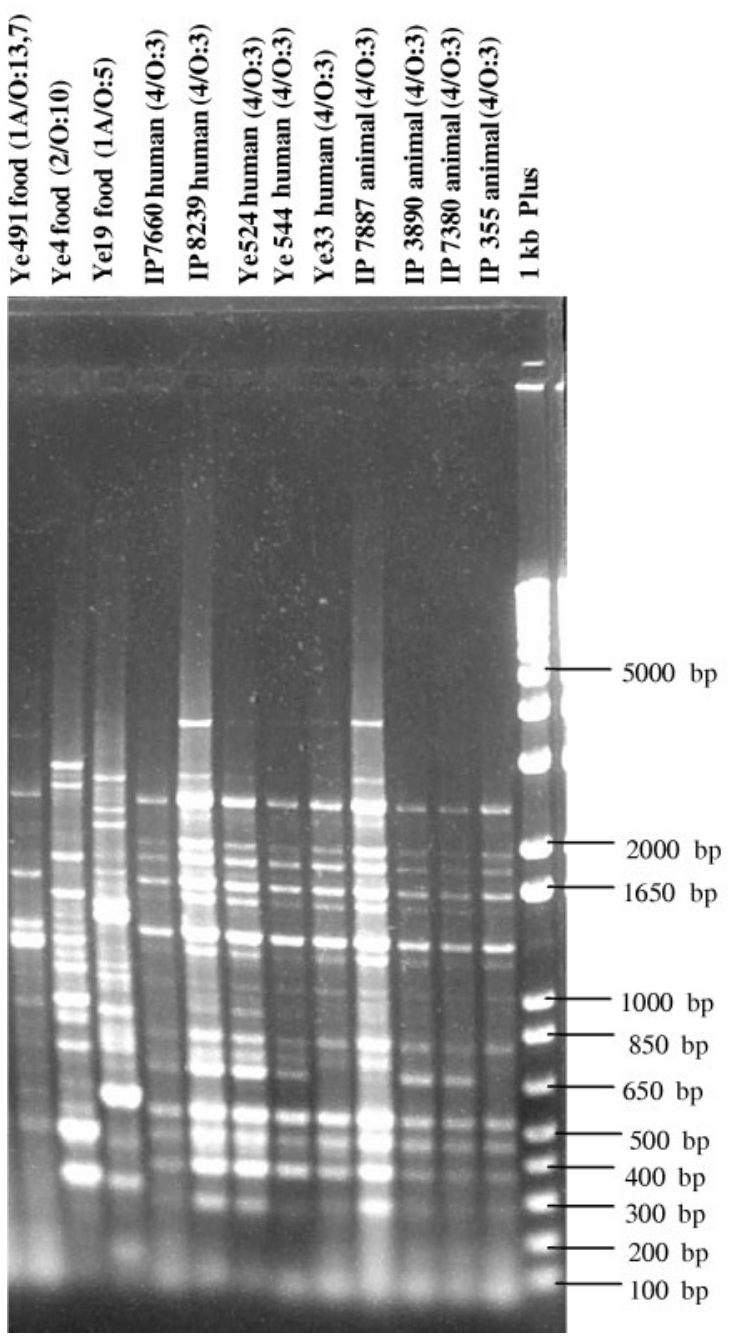

(b)

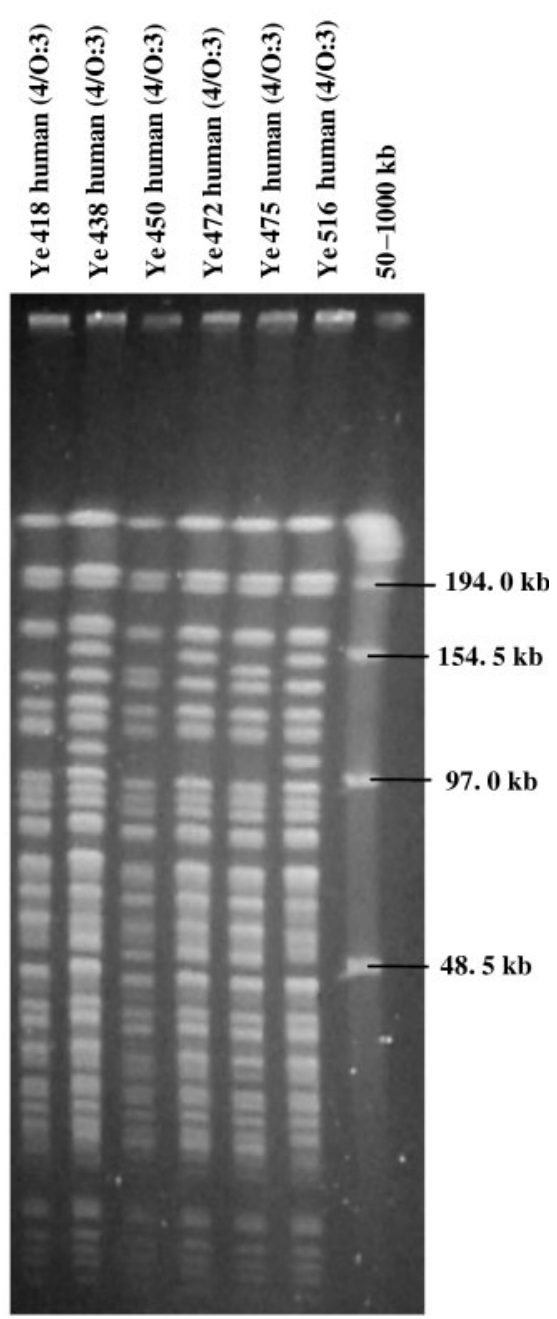

Fig. 1. (a) Representative gel of the band patterns generated by ERIC-PCR; $1.5 \%$ agarose gel. The right-hand lane shows the molecular-weight ladder, $1 \mathrm{~kb}$ Plus DNA. (b) PFGE in a $1.0 \%$ agarose gel, after genomic DNA digestion with Xbal. The right-hand lane shows the run of a molecular-weight ladder of 50-1000 kb. Both gels show representative strains of $Y$. enterocolitica that are listed above the figure along with their bio-serotype in parentheses.

(Bottone, 1999; Fredriksson-Ahomaa et al., 2004; Lambertz \& Danielsson-Tham, 2005) and indicating for the first time that pigs have been a source of $Y$. enterocolitica 4/O:3 human infections in Brazil. These data also corroborate earlier published work in which a high genetic similarity was demonstrated among $Y$. enterocolitica 4/O:3 strains (Fredriksson-Ahoma et al., 1999, 2001). On the other hand, the strains isolated from food were mostly from biotype $1 \mathrm{~A}$ and were more diverse regarding their fingerprints, both among themselves and relative to those isolated from humans and animals, as observed in previous studies (Najdenski et al., 1994; Iteman et al., 1996; Sachdeva \& Virdi, 2004).

Recently, Wojciech et al. (2004) have described the typing of $35 Y$. enterocolitica isolates by internal transcribed spacer
(ITS) profiling, ERIC- and repetitive extragenic palindromic (REP)-PCR. These authors observed that ERIC-PCR is a suitable technique for this purpose, generating similar results to the other two techniques used, although with a slightly lower discriminatory power. Also, Sachdeva \& Virdi (2004) used REP- and ERIC-PCR to assess the genomic heterogeneity among 81 strains of $Y$. enterocolitica biotype 1A isolated from India, Germany, France and the USA. Although the two techniques gave comparable results, ERIC fingerprints discriminated the strains better. To our knowledge, our work is the third that describes the use of ERIC-PCR to discriminate among $Y$. enterocolitica isolates, and the first to compare the results with PFGE, which is considered to be the gold-standard technique for this purpose. Additionally, ERIC-PCR grouped two food isolates with pathogenic characteristics close to the human and 
animal clusters, indicating that it may be possible to use it as a tool to group $Y$. enterocolitica strains by their virulence potential.

In conclusion, the group of results obtained in this work affords an improved view of the epidemiology and biology of $Y$. enterocolitica strains isolated from diverse sources, over 32 years, in various regions of Brazil. Furthermore, it reveals the unusual virulence potential of a bio-serotype $1 \mathrm{~A} / \mathrm{O}: 10$ strain isolated from food, indicating that biotype 1A strains may have been a neglected cause of infection in humans and animals in this country. The absence of pathogenic $Y$. enterocolitica 4/O :3 strains in food samples in Brazil may be explained by the limited sensitivity of isolation methods. PFGE was able to discriminate the strains better than the ERIC-PCR technique. However, ERIC-PCR discriminated between strains with virulence potential isolated from foodstuffs (Ye197 and Ye251) and those without this virulence potential, indicating that this technique may be used as a virulence-potential screening tool for $Y$. enterocolitica.

\section{ACKNOWLEDGEMENTS}

We thank Fundação de Amparo à Pesquisa do Estado de São Paulo (FAPESP) (Proc.02/05454-5) and the Conselho Nacional de Desenvolvimento Científico e Tecnológico (CNPq) (Proc.480189/ 2000-5) for financial support. During the course of this work, J.P.F. was supported by a scholarship from FAPESP (Proc.00/09175-8). We also thank Dr Clarice Queico Fujimura Leite, who allowed us to use the Gel Compare Program of her laboratory, and Henri Berghs for technical assistance in the use of this software. A small part of this work was published in the Proceedings of the eighth International Symposium on Yersinia (Falcão et al., 2003).

\section{REFERENCES}

Aleksic, S. \& Bockemühl, J. (1999). Yersinia and other enterobacteriaceae. In Manual of Clinical Microbiology, 7th edn, pp. 483-496. Edited by K. V. Forrest, J. H. Jorgensen, \& P. R. Murray. Washington, DC: American Society for Microbiology.

Andersen, J. K. \& Saunders, N. A. (1990). Epidemiological typing of Yersinia enterocolitica by analysis of restriction fragment length polymorphism with a cloned ribosomal RNA gene. J Med Microbiol 32, 179-187.

Bauab, T. M., Corrêa, E. F. \& Falcão, D. P. (1995). Evaluation of different techniques for the differentiation of pathogenic and non pathogenic strains of Yersinia enterocolitica. Rev Microbiol 26, 106-111.

Blumberg, H. M., Kiehlbauch, J. A. \& Wachsmuth, I. K. (1991). Molecular epidemiology of Yersinia enterocolitica $\mathrm{O}: 3$ infections: use of chromosomal DNA restriction fragment length polymorphism of rRNA genes. J Clin Microbiol 29, 2368-2374.

Bottone, E. J. (1999). Yersinia enterocolitica: overview and epidemiologic correlates. Microb Infect 1, 323-333.

Carniel, E. (1995). Chromosomal virulence factors of Yersinia: an update. Contrib Microbiol Immunol 3, 218-224.

Carniel, E. (2001). The Yersinia high-pathogenicity island: an ironuptake island. Microb Infect 3, 561-569.

Cornelis, G. R., Boland, A., Boyd, A. P., Geuijen, C., Iriarte, M., Neyt, C., Sory, M.-P. \& Stainier, I. (1998). The virulence plasmid of Yersinia, an antihost genome. Microbiol Mol Biol Rev 62 , 1315-1352.

Covone, M. G., Brocchi, M., Palla, E., Dias da Silveira, W., Rappuoli, R. \& Galeotti, C. L. (1998). Levels of expression and immunogenicity of attenuated Salmonella enterica serovar Typhimurium strains expressing Escherichia coli mutant heat-labile enterotoxin. Infect Immun 66, 224-231.

Falcão, D. P. (1987). Yersiniosis in Brazil. Summary of the data received at the Reference Laboratory for Yersinia in Brazil. Contrib Microbiol Immunol 9, 68-75.

Falcão, D. P. (1991). Occurrence of Yersinia spp. in foods in Brazil. Int J Food Microbiol 14, 179-182.

Falcão, J. P., Falcão, D. P., Correa, E. F. \& Brocchi, M. (2003). A virulence study of Yersinia enterocolitica $\mathrm{O}: 3$ isolated from sick humans and animals in Brazil using PCR and phenotypic tests. Adv Exp Med Biol 529, 341-343.

Falcão, J. P., Brocchi, M., Proença-Módena, J. L., Acrani, G. O., Correa, E. F. \& Falcão, D. P. (2004). Virulence characteristics and epidemiology of Yersinia enterocolitica and Yersiniae other than $Y$. pseudotuberculosis and Y. pestis isolated from water and sewage. J Appl Microbiol 96, 1230-1236.

Farmer, J. J., III, Carter, G. P., Miller, V. L., Falkow, S. \& Wachsmuth, I. K. (1992). Pyrazinamidase, CR-MOX agar, salicin fermentationesculin hydrolysis, and D-xylose fermentation for identifying pathogenic serotypes of Yersinia enterocolitica. J Clin Microbiol 30, 2589-2594.

Fredriksson-Ahomaa, M. \& Korkeala, H. (2003). Low occurrence of pathogenic Yersinia enterocolitica in clinical, food and environmental samples: a methodological problem. Clin Microbiol Rev 16, 220-229.

Fredriksson-Ahomaa, M., Autio, T. \& Korkeala, H. (1999). Efficient subtyping of Yersinia enterocolitica bioserotype 4/O:3 with pulsedfield gel eletrophoresis. Lett Appl Microbiol 29, 308-312.

Fredriksson-Ahomaa, M., Hallanvuo, S., Korte, T., Siitonen, A. \& Korkeala, H. (2001). Correspondence of genotypes of sporadic Yersinia enterocolitica bioserotype 4/O:3 strains from human and porcine sources. Epidemiol Infect 127, 37-47.

Fredriksson-Ahomaa, M., Koch, U., Klemm, C., Bucher, M. \& Stolle, A. (2004). Different genotypes of Yersinia enterocolitica 4/O: 3 strains widely distributed in butcher shops in the Munich area. Int J Food Microbiol 95, 89-94.

Fredriksson-Ahomaa, M., Stolle, A., Siitonen, A. \& Korkeala, H. (2006). Sporadic human Yersinia enterocolitica infections caused by bioserotype 4/O:3 originate mainly from pigs. J Med Microbiol 55, 747-749.

Grant, T., Bennett-Wood, V. \& Robins-Browne, R. M. (1998), Identification of virulence-associated characteristics in clinical isolates of Yersinia enterocolitica lacking classical virulence markers. Infect Immun 66, 1113-1120.

Greenwood, M. H. \& Hooper, W. L. (1990). Excretion of Yersinia spp. associated with consumption of pasteurized milk. Epidemiol Infect 104, 345-350.

Guiyoule, A., Rasoamanna, B., Buchrieser, C., Michel, P., Chanteau, S. \& Carniel, E. (1997). Recent emergence of new variants of Yersinia pestis in Madagascar. J Clin Microbiol 35, 2826-2833.

Hunter, P. R. \& Gaston, M. A. (1998). Numerical index of the discriminatory ability of typing systems: an application of Simpson's index of diversity. J Clin Microbiol 26, 2465-2466.

Ibrahim, A., Liesack, W., Griffiths, M. W. \& Robins-Browne, R. M. (1997). Development of a highly specific assay for rapid identification of pathogenic strains of Yersinia enterocolitica based on PCR amplification of Yersinia heat-stable enterotoxin gene (yst). J Clin Microbiol 35, 1636-1638. 
Iteman, L., Guiyoule, A. \& Carniel, E. (1996). Comparison of three molecular methods for typing and subtyping pathogenic Yersinia enterocolitica strains. J Med Microbiol 45, 48-56.

Kandolo, K. \& Wauters, G. (1985). Pyrazinamidase activity in Yersinia enterocolitica and related organisms. J Clin Microbiol 21, 980-982.

Kapperund, G. T., Nesbakken, T., Aleksic, S. \& Mollaret, H. H. (1990). Comparison of restriction endonuclease analysis and phenotypic typing methods for differentiation of $Y$. enterocolitica isolates. J Clin Microbiol 28, 1125-1131.

Lambertz, S. T. \& Danielsson-Tham, M. L. (2005). Identification and characterization of pathogenic Yersinia enterocolitica isolates by PCR and pulsed-field gel electrophoresis. Appl Environ Microbiol 71, 3674-3681.

Liu, S. L., Hessel, A. \& Sanderson, K. E. (1993). The XbaI-BlnI-CeuI genomic cleavage map of Salmonella typhimurium LT2 determined by double digestion, end labelling, and pulsed-field gel electrophoresis. J Bacteriol 175, 4104-4120.

Lobato, M. J., Landeras, E., Gonzales-Hevia, M. A. \& Mendonza, M. C. (1998). Genetic heterogeneity of clinical strains of Yersinia enterocolitica traced by ribotyping and relationships between ribotypes, serotypes, and biotypes. J Clin Microbiol 36, 3297-3301.

McIntyre, M. \& Nnochiri, E. (1986). A case of hospital-acquired Yersinia enterocolitica gastroenteritis. J Hosp Infect 7, 299-301.

Morris, J. G., Jr, Prado, V., Ferreccio, C., Robins-Browne, R. M., Bordun, A.-M., Cayazzo, M., Kay, B. A. \& Levine, M. M. (1991). Yersinia enterocolitica isolated from two cohorts of young children in Santiago, Chile: incidence of and lack of correlation between illness and proposed virulence factors. J Clin Microbiol 29, 2784-2788.

Najdenski, H., Iteman, I. \& Carniel, E. (1994). Efficient subtyping of pathogenic Yersinia enterocolitica strains by pulsed-field gel electrophoresis. J Clin Microbiol 32, 2913-2921.

Nakajima, H., Inoue, M., Mori, T., Itoh, K.-I., Arakawa, A. \& Watanabe, H. (1992). Detection and identification of Yersinia pseudotuberculosis and pathogenic Yersinia enterocolitica by an improved polymerase chain reaction method. J Clin Microbiol 30, 2484-2486.

National Commitee for Clinical Laboratory Standards (2001). Performance Standard for Antimicrobial Susceptibility Testing. Approved standard M100-S11. Wayne, PA: National Commitee for Clinical Laboratory Standards.

Nesbakken, T., Kapperud, G., Sorum, H. \& Dommarsnes, K. (1987). Structural variability of 40-50 MDa virulence plasmids from Yersinia enterocolitica. Acta Pathol Microbiol Immunol Scand 95, 167-173.

Nesbakken, T., Kapperud, G., Dommarsnes, K., Skurnik, M. \& Hornes, E. (1991). Comparative study of a DNA hybridization method and two isolation procedures for detection of Yersinia enterocolitica $\mathrm{O}: 3$ in naturally contaminated pork products. Appl Environ Microbiol 57, 389-394.

Nicolle, P., Mollaret, H. H. \& Brault, J. (1976). Nouveaux resultats sur la lysotypie de Yersinia enterocolitica portant sur plus de 4000 souches d'origines diverses. Rev Epidemiol Santé Publique 24, 479496 (in French).

Rasmussen, H. N., Rasmussen, O. F., Andersen, J. K. \& Olsen, J. E. (1994). Specific detection of pathogenic Yersinia enterocolitica by twostep PCR using hot-start and DMSO. Mol Cell Probes 8, 99-108.

Ratnam, S., Mercer, E., Picco, B., Parsons, S. \& Butler, R. (1982). A nosocomial outbreak of diarrheal disease due to Yersinia enterocolitica serotype O 5, biotype 1. J Infect Dis 145, 242-247.

Riley, G. \& Toma, S. (1989). Detection of pathogenic Yersinia enterocolitica by using Congo red-magnesium oxalate agar medium. J Clin Microbiol 27, 213-214.
Robins-Browne, R. M. (2001). Yersinia enterocolitica. In Food Microbiology Fundamentals and Frontiers, pp. 215-245. Edited by M. P. Doyle, L. R. Beuchat \& T. J. Montiville. Washington, DC: American Society for Microbiology.

Sachdeva, P. \& Virdi, J. S. (2004). Repetitive elements sequence (REP/ERIC)-PCR based genotyping of clinical and environmental strains of Yersinia enterocolitica biotype 1A reveal existence of limited number of clonal groups. FEMS Microbiol Lett 240, 193-201.

Saiki, R. K., Gelfand, D. H., Stoffel, S., Scharf, S. J., Higuchi, R., Horn, G. T., Mullis, K. B. \& Erlich, H. A. (1988). Primer-directed enzymatic amplification of DNA with a thermostable DNA polymerase. Science 239, 487-491.

Saken, E., Roggenkamp, A., Aleksic, S. \& Heeseman, J. (1994). Characterisation of pathogenic Yersinia enterocolitica serogroups by pulsed-field gel electrophoresis of genomic NotI restriction fragments. J Med Microbiol 41, 329-338.

Salyers, A. A. \& Whitt, D. D. (2002). Yersinia pestis, the cause of plague, and its relatives. In Bacterial Pathogenesis: a Molecular Approach. Edited by A. A. Salyers \& D. D. Whitt. Washington DC: American Society for Microbiology.

Sambrook, J. \& Russell, D. W. (2001). Molecular Cloning: a Laboratory Manual, 3rd edn. Cold Spring Harbor, NY: Cold Spring Harbor Laboratory.

Singh, I. \& Virdi, J. S. (2004). Production of Yersinia stable toxin (YST) and distribution of $y s t$ genes in biotype 1A strains of Yersinia enterocolitica. J Med Microbiol 53, 1065-1068.

Stock, I. \& Wiedemann, B. (1999). An in-vitro study of the antimicrobial susceptibilities of Yersinia enterocolitica and the definition of a database. J Antimicrob Chemother 43, 37-45.

Stock, I., Heisig, P. \& Wiedemann, B. (2000). Beta-lactamase expression in Yersinia enterocolitica biovars 1A, 1B, and 3. J Med Microbiol 49, 403-408.

Stock, I. \& Wiedemann, B. (2003). Natural antimicrobial susceptibilities and biochemical profiles of Yersinia enterocolitica-like strains: Y. frederiksenii, Y. intermedia, Y. kristensenii and Y. rohdei. FEMS Immunol Med Microbiol 38, 139-152.

Stock, I., Heisig, P. \& Wiedemann, B. (1999). Expression of betalactamases in Yersinia enterocolitica strains of biovars 2, 4 and 5 . J Med Microbiol 48, 1023-1027.

Sulakvelidze, A. (2000). Yersiniae other than Y.enterocolitica, Y. pseudotuberculosis and Y. pestis. the ignored species. Microb Infect 2, 497-513.

Tennant, S. M., Grant, T. H. A. \& Robins-Browne, R. M. (2003). Pathogenicity of Yersinia enterocolitica biotype 1A. FEMS Immunol Med Microbiol 38, 127-137.

Thoerner, P., Bin Kingombe, C. I., Bogli-Stuber, K., Bissig-Choisat, B., Wassenaar, T. M., Frey, J. \& Jemmi, T. (2003). PCR detection of virulence genes in Yersinia enterocolitica and Yersinia pseudotuberculosis and investigation of virulence gene distribution. Appl Environ Microbiol 69, 1810-1816.

Tibana, A., Warnken, M. B., Nunes, M. P., Ricciardi, I. D. \& Noleto, A. L. S. (1987). Occurrence of Yersinia species in raw and pasteurized milk in Rio de Janeiro, Brazil. J Food Prot 50, 580-583.

Tzelepi, E., Arvanitidou, M., Mavroidi, A. \& Tsakris, A. (1999). Antibiotic susceptibilities of Yersinia enterocolitica and $Y$. intermedia isolates from aquatic environments. J Med Microbiol 48, 157-160.

Versalovic, J., Koeuth, T. \& Lupski, J. R. (1991). Distribution of repetitive DNA sequences in eubacteria and application to fingerprinting of bacterial genomes. Nucleic Acids Res 19, 6823-6831.

Warnken, M. B., Nunes, M. P. \& Noleto, A. L. S. (1987). Incidence of Yersinia species in meat samples purchased in Rio de Janeiro, Brazil. J Food Prot 50, 578-579. 
Wauters, G., Aleksic, S., Charlier, J. \& Schulze, G. (1991). Somatic and flagellar antigens of Yersinia enterocolitica and related species. Contrib Microbiol Immunol 12, 239-243.

White, D. G., Zhao, S., Simjee, S., Wagner, D. D. \& McDermott, P. F. (2002). Antimicrobial resistance of foodborne pathogens. Microb Infect 4, 405-412.
Wojciech, L., Staroniewicz, Z., Jakubczak, A. \& Ugorski, M. (2004). Typing of Yersinia enterocolitica isolates by ITS profiling, REP- and ERIC-PCR. J Vet Med 51, 238-244.

Wren, B. W. \& Tabaqchali, S. (1990). Detection of pathogenic Yersinia enterocolitica by the polymerase chain reaction. Lancet 336, 693. 